\title{
Shunsuke Utsumi \\ Evolutionary community ecology of plant-associated arthropods in terrestrial ecosystems
}

Received: 5 December 2012/ Accepted: 11 March 2013/Published online: 9 April 2013

(C) The Ecological Society of Japan 2013

\begin{abstract}
In the 21st century, researchers have attempted a synthesis between community ecology and evolutionary biology. This emerging research area, which aims to synthesize community ecology and evolutionary biology, is evolutionary community ecology. Evolutionary community ecology addresses how intraspecific trait variation in community members is essential for predicting community properties and, how community properties are a key component of the selective forces that determine genetic and phenotypic variation in a community member. In this paper, I review recent findings in evolutionary community ecology in plantassociated arthropods in terrestrial ecosystems. I discuss roles of both genetic variation and phenotypic plasticity as a source of trait variation in plants in shaping plantassociated arthropod communities. Also, I discuss effects of genetic variation in herbivores on plant-associated arthropod communities. Furthermore, I highlight community context evolution in which multiple species interactions and community composition affect trait evolution of a community member. Finally, I argue that future studies should investigate a feedback loop between community and evolutionary dynamics beyond unidirectional studies on effects of evolution on a community or vice versa. This approach will provide major insights into mechanistic principles for making predictions of community ecology.
\end{abstract}

Keywords Biodiversity - Community genetics - Diffuse selection · Genotype-by-environment interaction · Herbivore-induced plant response

Shunsuke Utsumi is the recipient of the 16th Denzaburo Miyadi Award.

S. Utsumi $(\square)$

Uryu Experimental Forest, Field Science Center

for Northern Environment, Hokkaido University, Moshiri,

Horokanai, Hokkaido 0740741, Japan

E-mail: utsumi@fsc.hokudai.ac.jp

Tel.: +81-165-382125

Fax: + 81-165-382410

\section{Introduction}

Darwin (1859) used the metaphor of a "tangled bank" in the last paragraph of The Origin of Species, describing an image of a "tangled bank" made up of diverse species and complex interactions that "have all been produced by laws acting around us" and "are being evolved". This metaphor evokes dynamic interplays where organisms evolve in complex interactions among diverse species, and evolution affects the forms of these interactions. Community ecology and evolutionary biology have typically been studied in relative isolation from one another (Johnson and Stinchcombe 2007; Palkovacs and Post 2008). In the 20th century, multiple species interactions have mainly been addressed in community ecology (e.g., keystone predation, trophic cascade, and food web), while evolutionary biologists have tended to perform studies with a single species in isolation or in a direct pairwise interaction with another species, such as studies of coevolution. Evolutionary biology has focused on genetic and phenotypic variation within/among populations, whereas community ecology has typically assumed homogeneous populations, thereby excluding the evolutionary dynamics that result from natural selection on traits in individuals. In the 21 st century, however, researchers have attempted a synthesis between community ecology and evolutionary biology (Hairston et al. 2005; Whitham et al. 2006; Agrawal et al. 2007; Fussmann et al. 2007; Johnson and Stinchcombe 2007; Haloin and Strauss 2008; Urban et al. 2008; Post and Palkovacs 2009; Bolnick et al. 2011; Schoener 2011; Utsumi 2011; Ingram et al. 2012). At present, it is growingly recognized that the ecology of a community and the evolution of the species within it are interdependent. A major challenge in current biology is to integrate disciplines that address different levels of biological organization from subcellular mechanisms to functions in ecological communities and ecosystems. Thus, incorporating evolutionary biology into community ecology should be one of the core components of the integration. 
Several concepts address an integration of community ecology and evolutionary biology, such as evolving metacommunity (Urban et al. 2008), eco-evolutionary dynamics (Fussmann et al. 2007), diffuse (co)evolution (Strauss et al. 2005), community/ecosystem genetics (Whitham et al. 2006). These concepts partly overlap with each other, but none of them describe a comprehensive representation of a research area that addresses the integration of community ecology and evolutionary biology. Evolutionary community ecology is a more comprehensive phrase, representing the emerging research field that aim to synthesize community ecology and evolutionary biology. Evolutionary community ecology incorporates evolutionary principles, such as individual trait variation, to provide mechanistic insights into how ecological communities are organized across space and time (Berg and Ellers 2010; Ellers 2010; Lavergne et al. 2010). Evolutionary community ecology addresses how intra- and interspecific trait variation of the community member(s) is essential for predicting community properties (i.e., species composition, richness, abundance, and interactions), and how community properties are a key component of the selective forces that determine genetic and phenotypic variation at the individual level.

Plant-associated arthropod communities provide ideal natural systems for conducting research into evolutionary community ecology. Terrestrial plants support diverse arthropod species above- and below-ground. Herbivorous arthropods comprise the most diverse and abundant group of plant consumers, and hundreds of these consumer species may attack an individual plant. The leaves, branches, flowers, seeds, and roots are all utilized by a wide range of herbivorous arthropod species. Herbivorous arthropods are also attacked by diverse predatory and parasitoid arthropods. These arthropod species can interact directly and indirectly with one another on an individual plant, thereby shaping a plant-associated arthropod community. Importantly, arthropods often have a very short generation time, so the dynamics of the microevolution of plantassociated arthropods may be observable during a period of $<1$ year to decades, alongside the dynamics of community structure.

Here I review studies of evolutionary community ecology related to plant-associated arthropod communities, provide a discussion of my findings, and proposes future directions for this research area. This article highlights two reverse angles: (1) how variation in traits within species influences community properties, and (2) how community properties influence genetic diversity and realized phenotype of a single species through evolutionary processes. In particular, first I discuss roles of both genetic variation and phenotypic plasticity as a source of trait variation in plants in shaping plantassociated arthropod communities. I also discuss effects of genetic variation in herbivores on plant-associated arthropod communities. Second, I highlight community context evolution, in which multiple species interactions and community composition affect trait evolution of a community member. Finally, I argue future directions in terms of a feedback loop between community and evolutionary dynamics.

\section{Sources of plant trait variation and structuring arthropod communities}

Terrestrial plants commonly develop a wide range of phenotypic responses to attack by herbivores, and these herbivore-induced plant responses play an important role in the generation of phenotypic variation within and among individual plants (Karban and Baldwin 1997; Orians and Jones 2001; Ohgushi 2005; Utsumi et al. 2009b, 2010). Herbivory triggers plastic responses in plant morphology, growth and reproduction, nutritional status, and tissue chemistry (Karban and Baldwin 1997; Ohgushi 2005). For example, boring into a willow stem by the hepialid moth caterpillar (Endoclita excrescens), and folivory by the notodontid moth caterpillar (Clostera anastomosis) trigger new regrowth shoot production, while leaving apical tissues intact (Fig. 1; Utsumi and Ohgushi 2007; Utsumi et al. 2009a). The leaves of the regrowth shoots have a greater water and nitrogen content than those of non-regrowth shoots. As a result, overall abundance and species richness of herbivorous insects and predaceous arthropods increased on the regrowth shoots, and species composition differed between regrowth and non-regrowth shoots (Utsumi and Ohgushi 2009). Through the changes in plant phenotypes, the herbivore-induced plant responses provide a mechanistic basis for trait-mediated indirect interactions among plant-associated arthropods, including herbivores, predators, and parasitoids (Faeth 1986; Martinsen et al. 1998; Masters et al. 2001; Ando and Ohgushi 2008; Utsumi and Ohgushi 2008; Bukovinszky et al. 2009; Erb et al. 2011; Poelman et al. 2011), thereby affecting the properties of arthropod communities in terms of species composition, species richness, and overall abundance (Van Zandt and Agwaral 2004; Rodriuguez-Saona and Thaler 2005; Poelman et al. 2008, 2010; Utsumi and Ohgushi 2009).

On the other hand, natural plant populations also possess genetic variations in their ecologically important traits, such as morphology, growth, phenology, and chemistry (Berenbaum et al. 1986; Vrieling et al. 1991; Campbell 1996; O’Neil 1997; Olsson and Agren 2002; Barbour et al. 2009). A growing number of studies have shown that plant genotypes influence plant-arthropod interactions and community properties of plant-associated arthropods, including abundance, species richness, and species composition (Johnson and Agrawal 2005; Wimp et al. 2005; Bailey et al. 2006; Bangert et al. 2006; Whitham et al. 2006; Barbour et al. 2009; Utsumi et al. 2011). Both the induced plant responses and plant genetic variations are likely to have qualitatively similar effects on structuring plant-associated arthropod communities (McGuire and Johnson 2006; Utsumi et al. 


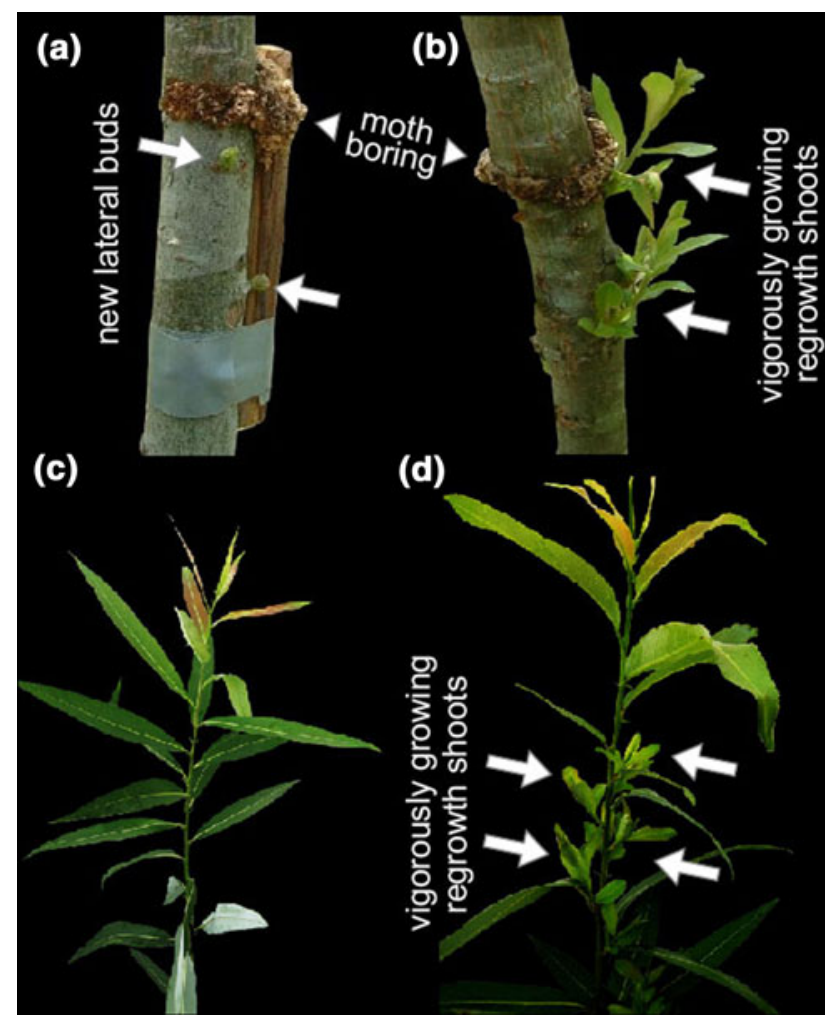

Fig. 1 Herbivore-induced willow regrowth. After stem-boring by the moth caterpillar (Endoclita excrescence), lateral buds are newly produced (a), and then regrowth shoots are vigorously developed from the lateral buds (b). Without damage, no regrowth shoots are produced (c), and folivory by the moth caterpillar (Clostera anastomosis), triggers the production of regrowth shoots (d). It should be noted that both types of damage trigger regrowth response, leaving apical tissue intact

2009b). However, to date, these two aspects have always been explored separately. McGuire and Johnson (2006) argued that plant genotypic effect is more important than effects of induced plant responses, based on a quantitative review of several experimental studies, but these studies were often designed to increase the contrast between plant genotypes in a wide geographic range. Therefore, the results of such a comparison may be dependent on the collection of different genotypes used in the experiments, which may not reflect the actual ecological community in the field. More importantly, the genetic effects of plants on arthropod communities include the effects of induced plant responses, because the responses of plants are based on a genetic background acquired through evolutionary processes. Thus, plant genetics and induced plant responses are not independent. The induced plant response is one form of phenotypic plasticity, where an identical genotype can express different phenotypes depending on the biotic and abiotic environments (Agrawal 2001; Fordyce 2006; Berg and Ellers 2010). Phenotypic plasticity has received much attention from evolutionary biologists, and the involvement of genetic variation in phenotypic plasticity is formulated as a genotype-by-environment interaction
(Via and Lande 1985; Sultan and Bazzaz 1993; de Jong 1995; Van Kleunen and Fischer 2005).

Indeed, induced plant responses to insect herbivores have been shown to be genetically variable and heritable (Zangerl and Berenbaum 1990; van Dam and Vrieling 1994; English-Loeb et al. 1998; Underwood et al. 2000; Sauge et al. 2006). Juenger and Bergelson (2000) demonstrated significant additive genetic variation in changes in flowering phenology and branch production of a scarlet gilia in response to herbivory. There was also a marginally significant additive genetic variance in fitness of herbivore-damaged plants, but not in fitness of control plants. Agrawal et al. (2002) reported additive genetic variation in the inducibility of defensive traits (i.e., plasticity of the glucosinolate concentration) in wild radish and in induced resistance to a specialist herbivore (Pieris rapae). Interestingly, Agrawal et al. (2002) detected no genetic variation in glucosinolate concentration in the absence of herbivory, whereas there was significant additive genetic variation in the presence of herbivory. They argued that plants might allocate little to their constitutive defense due to high costs, resulting in a lack of genetic variation in defensive traits without herbivory. Juenger and Bergelson (2000) also reported that genetic variation was detected in traits of damaged plants. Genetic variation in induced plant responses may be widespread in natural plant populations (Zangerl and Berenbaum 1990; van Dam and Vrieling 1994; Havill and Raffa 1999; Agrawal et al. 2002; Bingham and Agrawal 2010; Snoeren et al. 2010). Thus, these findings suggest that plants have a potential for continued evolution of induced response. Furthermore, several studies have shown the fitness costs of maintaining inducibility in the absence of herbivores and the benefits of induction in the presence of herbivores (Baldwin 1998; Agrawal et al. 2002; Tian et al. 2003; Zavala and Baldwin 2004; Gómez et al. 2007; but see Karban 1993). These results suggest that herbivore-induced plant responses are likely to be adaptive under the environment with herbivores. Hence, genetic variation in induction may be maintained under variable selection imposed by herbivores.

Indirect evidence also suggests potentially adaptive, fine-tuned induced plant responses against diverse attackers. Herbivore-induced plant responses are often highly specific to attack by a particular herbivore species, as shown by the differential responses of plants to attack by different herbivores (Karban and Baldwin 1997; Van Zandt and Agrawal 2004; Voelckel and Baldwin 2004; Travers-Martin and Müller 2007; Agrawal 2011). For example, induced responses in a wild radish (Raphanus raphanistrum) exhibited specificity for the type of herbivore, and there was differential induced resistance following attack by four lepidopteran species (Agrawal 2000) but minimal induction following artificial clipping by scissors (Agrawal 1998). Responses to actual herbivory often differ qualitatively and/or quantitatively from responses to artificial defoliation (Hartley 
and Lawton 1987; Turlings et al. 1990; Krause and Raffa 1992; Agrawal et al. 1999; Pavia and Toth 2000). Several studies demonstrated that the application of herbivore regurgitant to artificially damaged plant tissues can more closely simulate actual feeding due to chemical elicitors present in the saliva (Lin et al. 1990; Alborn et al. 1997; Korth and Dixon 1997; McCloud and Baldwin 1997). This specificity was also reported in plant compensatory responses, that is, regrowth and/or reproduction following herbivory to compensate for damaged tissue (Strauss and Agrawal 1999; Utsumi and Ohgushi 2007). Utsumi and Ohgushi (2007) showed that compensatory regrowth in terms of the number of newly emerged lateral shoots of willows was more strongly enhanced by boring of a swift moth caterpillar than artificial boring. Utsumi et al. (2013) compared the expression of the willow regrowth response after herbivory by each of seven herbivore species and reported that regrowth induction was highly dependent on herbivore species. Similar to plant resistance, plant compensatory responses may be affected by factors related to natural herbivory, such as specific feeding behaviors or chemical cues present in herbivore saliva (McNaughton 1983).

Overall, future studies should adopt the framework of genotype-by-environment interactions $(\mathrm{G} \times \mathrm{E})$ rather than dichotomy as genetic effects versus phenotypic plasticity effects, for an understanding of community consequences of traits. Researchers should focus on how the presence or absence of a particular herbivore alters the mean and variance of a phenotype within and between plant populations that are genetically structured through evolutionary processes.

\section{Effects of plant genetic and phenotypic diversity on arthropod community}

Above, I discussed the source of plant trait variation and how arthropod communities are shaped on plants with distinct traits. Next, I highlight effects of diversity of plant genotypes and phenotypes within a population on arthropod community structure. Several recent studies have addressed how plant genetic diversity influences trophic interactions and community structure of plant-associated arthropods (Crutsinger et al. 2006; Johnson et al. 2006; Crawford et al. 2007; Cook-Patton et al. 2011; Tack and Roslin 2011; Utsumi et al. 2011; Castagneyrol et al. 2012). Ecological mechanisms of the influence of genetic diversity are additive and nonadditive mechanisms. In additive mechanisms, the ecological response of individual genotypes in a monoculture plot and the initial relative abundance of each genotype in a population are jointly sufficient for predicting the same ecological response in a genetically diverse plot. In non-additive mechanisms, however, the response in a genetically diverse plot is not predictable based solely on measurements of the same ecological response in genetically uniform plots (Hughes et al.
2008). To exemplify non-additive mechanisms, I discuss my common garden experiment, which investigated effects of genotypic diversity of the tall goldenrod (Solidago altissima) on aphid population abundance. We prepared single genotype plots and multiple genotype plots that consisted of individually potted $S$. altissima in a common garden in Minnesota in the USA (Utsumi et al. 2011). The potted setting eliminated belowground interactions among plant genotypes. Natural populations of $S$. altissima in North America exhibit genotypic variation in their resistance to herbivorous insect species (Craig et al. 2011; Utsumi et al. 2011). In the common garden experiment, non-additive, synergistic effects of plant genotypic diversity on population size of the specialist aphid (Uroleucon nigrotuberculatum) were detected. The synergistic effects were demonstrated by greater aphid abundance than that expected from an additive effect, which is the sum of appropriate mean values from the single genotype plots for each genotype in the multiple genotype plots (Fig. 2; Utsumi et al. 2011). Counter-intuitively, this non-additive increase in multiple genotype plots was due to an increase in the aphid abundance on resistant plant genotypes rather than susceptible genotypes. In this experiment, additional multiple-genotype-with-cage plots were also produced, in which each plant was individually caged to prevent aphid movement among plants. In the cage plots, the aphid abundance was also greater than in single genotype plots, which was probably due to predator removal, although the aphid growth rates were similar among genotypes. These results suggest that genetically diverse plants would enhance source-sink dynamics of aphid populations: aphids spilled over from plant genotypes where their reproduction was high (i.e., susceptible genotypes) to genotypes where their reproduction was low (i.e., resistant genotypes). As a result, a genetically diverse plant population synergistically increased aphid population size.

Several experimental studies have reported both additive effects (Johnson et al. 2006) and synergistic non-additive effects (Crutsinger et al. 2006, 2008;

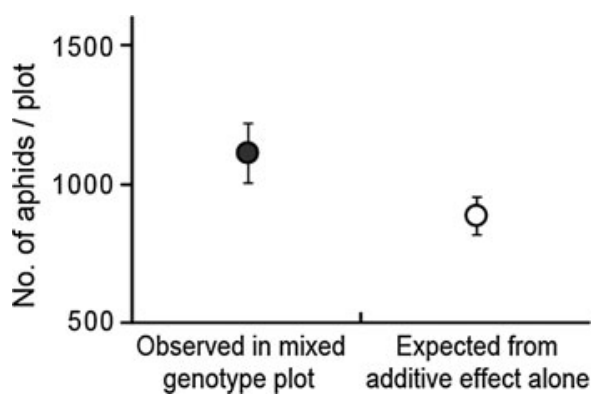

Fig. 2 The effect of host plant genotypic diversity on population sizes of the specialist aphid (Uroleucon nigrotuberculatum). Expected number from additive effect of genotypes alone vs. observed number in multiple genotype plots. Error bars indicate SE. Reproduced from Utsumi et al. (2011) 
Johnson et al. 2006; Genung et al. 2010) of plant genotypic diversity on the properties of plant-associated arthropod communities. Variance of phenotypic values within a plant population may be one of the major factors responsible for the magnitude of the non-additive effects of genetic diversity (Underwood 2004, 2009). In particular, genetic variance in plant traits influencing competition or facilitation among genotypes (Crutsinger et al. 2006; Genung et al. 2010) and/or source-sink dynamics of plant-associated arthropods (Underwood 2004; Utsumi et al. 2011) may be important for nonadditive effects of genetic diversity.

Herbivore-induced plant responses can also lead to phenotypic diversity within a plant individual/population even when plant genetic variation is lacking. This is because herbivory is generally distributed locally and varies in intensity within and among individual plants. Subsequent changes in morphology, chemistry, and growth patterns in response to local herbivory often cause resource quality to be more heterogeneous for herbivores (Orians and Jones 2001; Viswanathan and Thaler 2004; Utsumi et al. 2009b). As a result, phenotypic diversity generated by induced plant responses can contribute to increase in species richness and abundance of plant-associated arthropods. In our common garden experiment, boring damage by a swift moth caterpillar (E. excrescens) and artificial cutting of $25 \%$ of the stems were used to represent partial herbivory within individual willow trees, while $100 \%$ cutting of stems was applied to represent severe herbivory of whole individual trees (Utsumi et al. 2009b). These treatments stimulated a willow regrowth response that depended on damage intensity, resulting in full compensation for biomass loss due to each of herbivory treatments and similar biomass among treatments. However, moth boring and $25 \%$ cutting led to significant increases in within-tree variation for the foliar nitrogen and species richness of herbivores. However, $100 \%$ cutting did not influence herbivore species richness compared with control trees, although $100 \%$ cutting led to greater nitrogen content than that in the controls due to a strong regrowth response. Importantly, community composition of herbivore species differed among the following three groups: (1) bored and $25 \%$ cut, (2) $100 \%$ cut, and (3) control trees (Fig. 3a). In the ordination plot, communities on bored and $25 \%$ cutting trees were located in the middle between $100 \%$ cut and control trees (Fig. 3a). These results indicate that distinct herbivore species on $100 \%$ cutting and control trees combinably accumulated on bored or $25 \%$ cutting trees, leading to an increase in species richness on these plants. Therefore, herbivore-induced plant responses could expand niche space for herbivores. Furthermore, these changes also cascaded upward to predator community composition (Fig. 3b). This study also suggests that variation in damage intensity within a plant population may contribute to the maintenance of local species diversity of plant-associated arthropods at the spatial scale of a plant population. This notion is also supported by Kersch-Becker and Lewinsohn (2012), in which they conducted a partial clipping and overall clipping experiment on grassland in a Cerrado reserve in Brazil.

Recent review articles (Bolnick et al. 2011; Violle et al. 2012) emphasize the importance of the degree of trait variances within a population as underlying mechanisms for a wide range of ecological phenomena, including population dynamics, community structure, and ecosystem function. The integration of knowledge regarding effects of genotypic diversity and phenotypic plasticity on community properties demands that future studies should quantitatively investigate how trait variance in a population is regulated via $\mathrm{G} \times \mathrm{E}$ functions and how it shapes community structure.

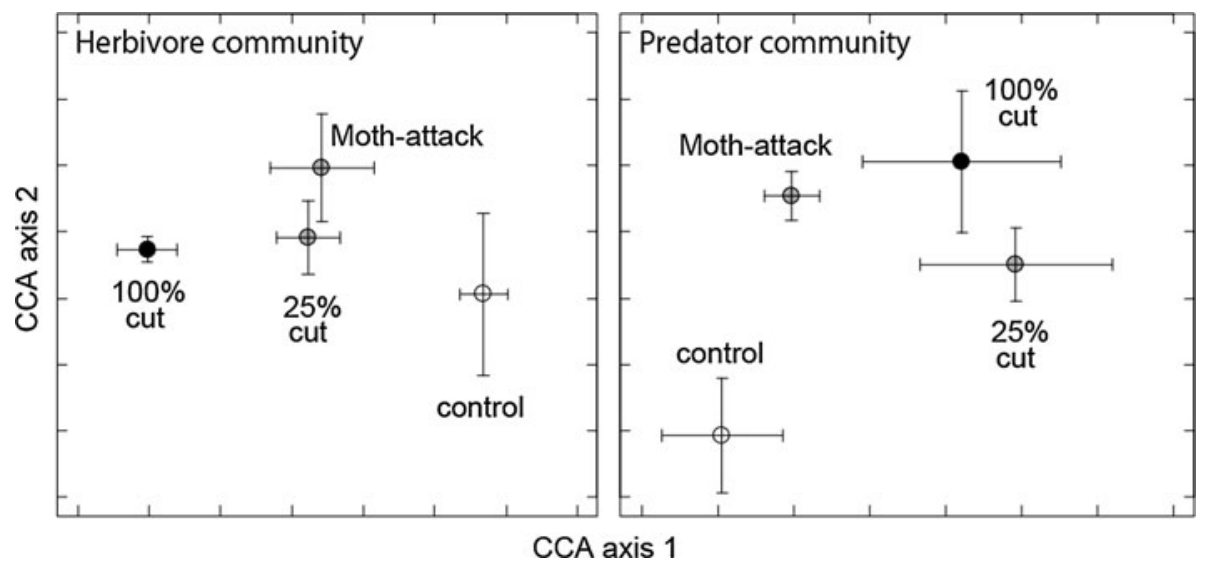

Fig. 3 Canonical correspondence analysis (CCA) ordination plots for herbivore communities and predator communities. Means and SE for communities on a single experimental tree in each treatment are represented. The data set with individual numbers of each species was analyzed. See details in text. Reproduced from Utsumi et al. (2009b) 


\section{Effects of herbivore genetics on arthropod communities}

Researchers have overwhelmingly focused on plant trait variation and its resultant effects on the upper trophic levels, as discussed above. However, not only plant traits but also animal traits may influence species interactions and community structure of plant-associated arthropods. As discussed about specificity in plant induction above, herbivore-induced plant responses are dependent on a variety of herbivory characteristics, such as the amount of damage, type of damage, timing of damage, and chemical contents of insect saliva. Thus, genetic variation in herbivore traits linked with such characteristics could affect herbivore-induced plant responses, resulting in influencing arthropod communities. Because genetic variation in induced plant responses may also be widespread in plant species, interactive effects of both genotypes in plants and herbivores may be important for shaping arthropod communities.

Kant et al. (2008) reported the existence of intraspecific variation in herbivore traits responsible for plant induction. Kant et al. (2008) developed three distinct lines of the spider mite (Tetranychus urticae) from natural populations. The first line induced jasmonate (JA)dependent defenses in tomato plants and was susceptible to these defenses. The second line also induced JA defenses but was resistant to them. The third line was susceptible to JA defenses but inhibited their induction. This variation might be due to differences in the elicitor components produced by the spider mite. Takabayashi et al. (2000) also found that intraspecific variation in the spider mite ( $T$. urticae) influenced the attraction of predatory mites to herbivore-induced plant volatiles. In a plant-aphid system, Gianoli et al. (1997) reported that the magnitude of induction of hydroxamic acids in wheat plants in response to attack by the cereal aphid (Sitobion avenae) was dependent on the interaction between wheat genotypes and aphid genotypes. Such intraspecific genetic variation in herbivore traits responsible for induction of plant responses would lead to differences in the subsequent plant-mediated effects among plant-associated arthropods.

I conducted a common garden experiment to examine indirect effects of genetic variation within a herbivore species on other arthropod species. Allopatric natural populations of the leaf beetle (Plagiodera versicolora) have evolutionarily developed different feeding preferences within a host species, which range from an exclusive preference for new leaves to a lack of preference among leaf-age types (non-preference) (Utsumi et al. 2009a, 2013). This variation in preference is likely to be linked with differential foraging behavior (Utsumi 2011). The exclusive preference beetles intensively forage for new, non-fully expanded willow leaves in the field, whereas the non-preference beetles feed on new and mature leaves. Herbivory by $P$. versicolora triggers the production of phenolic compounds in willows (Fields and Orians 2006). In general, the patterns of herbivore- induced plant responses often depend on the leaf age (Karban and Baldwin 1997; Mattiacci et al. 2001; Anderson and Agrell 2005). Thus, we predict that genetic variation in the leaf beetle preference may influence plant-mediated indirect effects on other herbivores on willows. In the common garden experiment, five willow genotypes and two lines of $P$. versicolora populations (i.e., the exclusive preference line and the non-preference line) were prepared, and five adults of each line were inoculated as a prior attacker onto each willow genotype, which were individually caged. Five days after inoculation of the leaf beetles on the willow genotypes, the leaf beetles were removed and subsequent colonization by a conspecific leaf beetle and the leaf miner (Phyllocnistis saligna) were investigated. There were significant interaction effects between willow genotype and leaf beetle line on abundance of both of the subsequently colonizing herbivores were detected (Utsumi et al. unpublished data). Interestingly, in the absence of prior herbivory by leaf beetles, no significant effects of willow genotypes on subsequent colonization by the leaf beetles and leaf miners were detected. Profound plant genetic effects on arthropod communities as previously reported may arise from interactions between genetic variations in traits of induced plant responses and herbivores.

The above examples demonstrate the effect of genetic variation on reciprocal species interactions [i.e., genotype-by-genotype $(\mathrm{G} \times \mathrm{G})$ interactions]. Overall, genetic variation in both plants and arthropod species can regulate variation in plant phenotypes, leading to $G \times G$ interactions (Agrawal 2001; Tétrad-Jones et al. 2007). Moreover, $\mathrm{G} \times \mathrm{G}$ interactions could affect direct and indirect species interactions, and may have a large impact on local community structure of plant-associated arthropods. $G \times G$ interactions are also likely to be dependent on the biotic and abiotic environment $(\mathrm{G} \times$ $\mathrm{G} \times \mathrm{E}$; Agrawal 2001; Tétrad-Jones et al. 2007). However, to date, empirical studies with a framework of $\mathrm{G} \times \mathrm{G} \times \mathrm{E}$ are still very rare in a community context. Future studies should consider $\mathrm{G} \times \mathrm{G} \times \mathrm{E}$ as a general framework in evolutionary community ecology. In addition, no studies have included effects of genetic diversity in arthropod species. Future studies should also pay attention to genetic diversity across multiple trophic levels.

\section{Community context evolution}

The previous sections highlighted how trait variation affects arthropod community structure. In contrast, this section discusses how ecological communities influence trait evolution in plant-arthropod systems. In order to synthesize community ecology and evolutionary biology, it is necessary to understand how species evolve in diverse and complex interactions in ecological communities. However, empirical studies on evolution in a 
community context are much fewer compared to the large number of studies on trait effects on shaping communities. Here I focus on empirical evidence regarding effects of multiple species interactions and community composition on natural selection as community context evolution.

Although the idea that species embedded in a multiple-species community exhibit traits that are evolutionarily shaped by multiple species interactions is not new, researchers have only recently demonstrated evolution in a community context. The majority of these studies have focused on effects of multiple herbivore species on plant trait evolution (Pilson 1996; Juenger and Bergelson 1998; Stinchcombe and Rausher 2001, 2002; Strauss et al. 2005; Leimu and Koricheva 2006). For example, Lankau and Strauss (2008) experimentally demonstrated that the selective value of the concentration of a defensive chemical compound (glucosinolate) of the black mustard (Brassica nigra) was dependent on the presence of a generalist mollusk (Deroceras reticulatum), a specialist aphid (Brevicoryne brassicae), or both. More recently, Züst et al. (2012) studied the evolution of defensive chemicals in natural populations of Arabidopsis thaliana (Brassicae) in Europe. They compared the geographic variation in the profiles of glucosinolates with 39 years of field data related to abundance of two specialist aphid species. The aphid (B. brassicae) predominated in areas where the plants produced glucosinolates with four-carbon side chains, whereas the aphid (Lipaphis erysimi) predominated in areas where plants produced glucosinolates with threecarbon side chains. Züst et al. also tested whether a causal link might underlie this geographic pattern by conducting selection experiments manipulating aphid community. After five generations of selection, herbivory by each aphid species selected for plant genotypes with glucosinolate profiles identical to those in the field locations where each aphid species dominated. Simultaneously, the no aphid treatment selected for a genotype with low levels of glucosinolates, whereas this genotype was excluded from populations exposed to any aphid treatments. Thus, aphids impose selection on the evolution of the defensive traits, and relative abundance of two aphid species in a local community governs evolution of defensive chemicals. Most studies have only conducted selection experiments in common gardens where they manipulated a few community members. However, this study provides strong evidence that a multiple-species community actually imposes and modulates selection for a plant trait in the field, based on consistent results shown by a large scale field pattern and a selection experiment.

On the other hand, very few studies have shown that arthropod communities can influence trait evolution in an arthropod species within a community. Utsumi et al. (2009a, 2013) demonstrated that evolution of a feeding trait of a herbivorous insect species occurred in a herbivore community context (Fig. 4). Willows (Salicaceae) produce new regrowth shoots in response to attack by
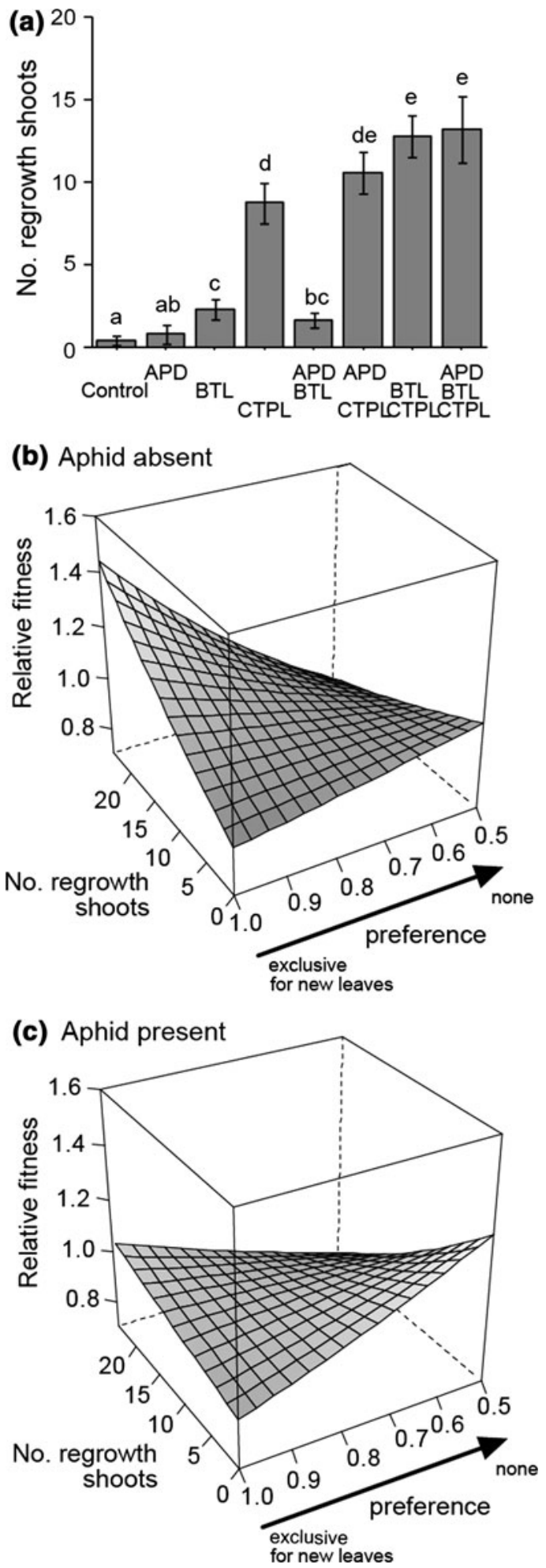

Fig. 4 Results of mesocosm selection experiment. a Amongcommunity differences in willow regrowth. APD aphid, BTL beetle, CTPL caterpillar. Bars are mean \pm SE. Different letters indicate significant differences $(p<0.05)$. b Fitness landscape of $P$. versicolora with respect to their preference and willow regrowth in the absence of aphids, and $\mathbf{c}$ in the presence of aphids. Lines from left to right on the surface can be interpreted as predicted selection gradients along regrowth intensity. Reproduced from Utsumi et al. (2013) 
some herbivore species (e.g., notodontid and hepialid caterpillars, and a cecidomyiid sawfly), but not to attack by other species (e.g., arctiid caterpillar, lace bugs, and aphids). Furthermore, regrowth intensity depends both on the plant's induced response to different herbivore species and the integration of those species in the community (Utsumi et al. 2013). A herbivore-removal experiment in the field and a herbivore-inoculation experiment in the greenhouse showed that herbivore community composition determined the degree of herbivore-induced regrowth of the local willow populations in the field. Herbivore-induced regrowth involved phenological changes in new leaf production, where the period of new leaf production expanded dramatically (Nakamura et al. 2003; Utsumi et al. 2009a, 2013). Where new leaves are seasonally abundant due to strong willow regrowth, populations of the specialist leaf beetle $(P$. versicolora) develop exclusive preference for new leaves. However, other populations show nonpreference for leaf-age types where new leaves are scarce due to weak willow regrowth (Utsumi et al. 2009a, 2013). In addition, herbivory by larvae and adults of $P$. versicolora did not trigger significant willow regrowth responses. Therefore, differences in composition of local herbivore communities lead to divergent trait evolution in leaf beetle ( $P$. versicolora) populations via plantmediated indirect interactions. Utsumi et al. (2013) also confirmed the evolutionary process of the leaf beetle by a mesocosm selection experiment, manipulating three other herbivore species with all possible combinations (Fig. 4). This selection experiment also showed the aphid (Pterocomma pilosum), whose attacks do not trigger willow regrowth response, imposed a reversal but relatively weak selection toward non-preference among leaf-age types. Because the aphid colonizes the growing apical regions of shoots, the aphids may have reduced quality of new leaves. Subsequently, this reduction in new leaf quality may have negatively affected the leaf beetles that have exclusive preference for new leaves, whereas lower-quality new leaves had no effect on the non-preference leaf beetles. Thus, the selective value of the feeding trait depends on multiple species interactions present in diverse natural communities. This study revealed that community composition shapes the selection regime for evolution in the field through trait-mediated indirect interactions.

Bonte et al. (2010) suggested that belowground communities may impose selection on the aboveground herbivores mediated by induced plant responses. They bred spider mites ( $T$. urticae) for 15 generations ( $<1$ year) on snap beans (Phaseolus vulgaris), with rootfeeding nematodes, arbuscular mycorrhizal fungi, or no biota. The belowground biota treatments had different effects on plant phenotypes, such as biomass, shoot water content, and foliar nitrogen and phosphorous content. Subsequently, Bonte et al. conducted a reciprocal experiment using these spider mite lines that had been kept on the differently treated plants. Spider mite fitness (i.e., growth rate) was higher on plants that received the same belowground treatment as the one they experienced during selection. This study did not create a combination treatment of multiple belowground components, such as an inclusion of both fungi and nematode, but it did suggest that belowground community composition may impose selection for traits in aboveground herbivores via the modification of plant phenotypes.

Using the inquiline community of pitcher plant instead of a plant-insect system, terHorst (2010) demonstrated multispecies effects on evolution of cell size of protozoan species (Colpoda sp.) by a selection experiment. The presence of the predator mosquito larva (Wyeomyia smithii) or the competitor protozoan species (Pseudocyrtolophosis alpestris) similarly imposed selection toward smaller Colpoda cell size than did the Colpoda monoculture. Although the exact mechanisms are unknown, smaller individuals might be harder for the filter-feeding mosquito larvae to capture, and might also use resources more efficiently in the presence of the large competitors. In contrast, the presence of both predators and competitors altered the evolutionary trajectories. Colpoda modified its behavior and utilized the bottom refuge in response to the presence of predators, but the competitor did not. Thus, only the competitor was subject to increased predation, and Colpoda experienced decreased predation and interspecific competition. As a result, cell size evolved as large as the degree in the monoculture.

The above examples demonstrate diffuse selection, in which community composition (or the presence/absence of the third species) alters the selection gradient for a focal trait of a community member (Iwao and Rausher 1997; Strauss et al. 2005; Haloin and Strauss 2008). In particular, studies by Utsumi et al. (2013), Bonte et al. (2010), and terHorst (2010) showed that trait-mediated indirect interactions, which are very common in various ecosystems, were the underlying mechanisms for diffuse selection. If future studies focus on evolutionary consequences of trait-mediated indirect interactions, we may discover that diffuse selection of plant-associated arthropods is a common phenomenon in nature. In addition, diffuse selection may be an important mechanism underlying the maintenance and origin of biodiversity, including intraspecific genetic diversity, as shown by Utsumi et al. (2013). The variation in species composition among local communities (i.e., beta diversity) might lead to within-species genetic diversity. It should also be noted that there are two other mechanisms whereby the community context affects species evolution if we focus on multiple traits. Evolution will also be diffuse if community context alters (1) the selection gradient on any trait that is genetically correlated with the focal trait, and (2) genetic variance-covariance matrix of traits (see Strauss et al. 2005; Leimu and Koricheva 2006; Haloin and Strauss 2008). 


\section{Effects of species diversity on evolution}

Not only community composition but also species diversity per se within a local community (i.e., alpha diversity) may be important for evolution of a community member (Fig. 5). There are three possible hypotheses. The first hypothesis is that species diversity may act as a source of diversifying selection on a community member: diversity begets diversity hypothesis. If different genotypes of the focal species display a different response in interactions with diverse species, fine-scale environmental variation in interactions within a local community will impose variable selection pressure on the focal species population. As a result, genetic diversity may be maintained (Vavrek 1998; Vellend and Geber 2005; Ellers 2010). On the other hand, the opposite effect of species diversity on genetic diversity of single species may be possible. The second hypothesis, niche variation hypothesis, proposes that a diverse community constraints genetic diversity in a single species. This is because a diverse community may inhibit the focal species from exploiting different niches and cause stabilizing selection (Vellend and Geber 2005; Ellers 2010). Furthermore, I also propose the third hypothesis: directional selection hypothesis. The degree of local species diversity may evolutionarily determine the average trait status of a community member, although the above two hypotheses focus on genetic variation within a population. In this case, differences in local species diversity among communities may result in genetic diversity among populations. For example, if one species has a genetic trade-off between intra- and interspecific competitive ability, genotypes with a strong interspecific competitive ability can evolve in a high species diversity community, and low species diversity may benefit genotypes with a weak interspecific competitive ability. Lankau and Strauss (2007) reported findings that partially support this hypothesis, although they did not perform an experimental manipulation of species diversity levels. Brassica nigra has genetic variation in sinigrin (allylglucosinolate) concentration. High sinigrin concentration was advantageous for interspecific competition but disadvantageous for intraspecific competition (Lankau and Strauss 2007). As a result, high-sinigrin genotypes had a greater fitness than low-sinigrin genotypes in diverse heterospecific plant communities. In contrast, low-sinigrin genotypes had a greater fitness than the latter genotypes in a monoculture of B. nigra, regardless of the sinigrin level of the surrounding $B$. nigra. I can also speculate another case in the third hypothesis, considering connections among species diversity, ecosystem function, and evolution. Extensive research has shown that ecosystem processes, such as productivity, nutrient cycling rate, and consumer biomass, increase with local species diversity (Duffy et al. 2007; Loreau 2010). If selection for a community member depends on a level of an ecosystem function gradient, species diversity may indirectly alter
Fig. 5 A schematic illustration of three hypotheses about species diversity effects on evolution and genetic diversity (a)

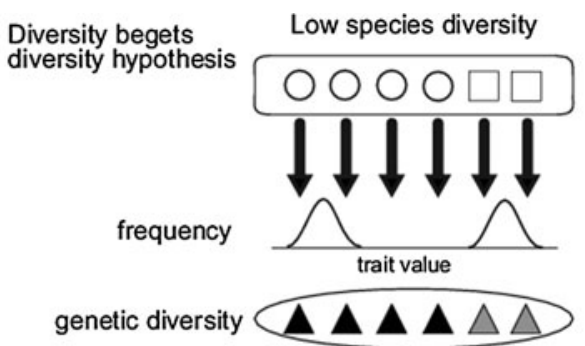

(b) Niche variation hypothesis

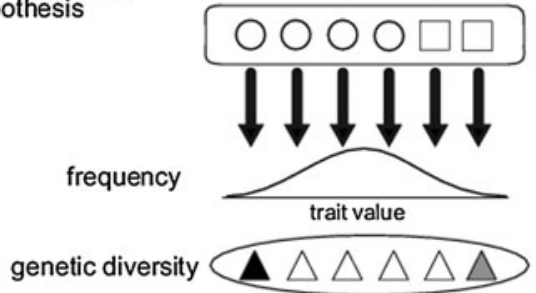

(c) Directional selection hypothesis

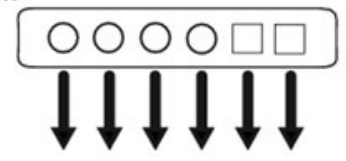

frequency

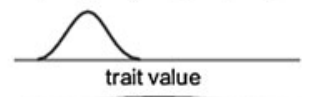

trait value

genetic diversity $\Delta \triangle \Delta \triangle \Delta$
High species diversity
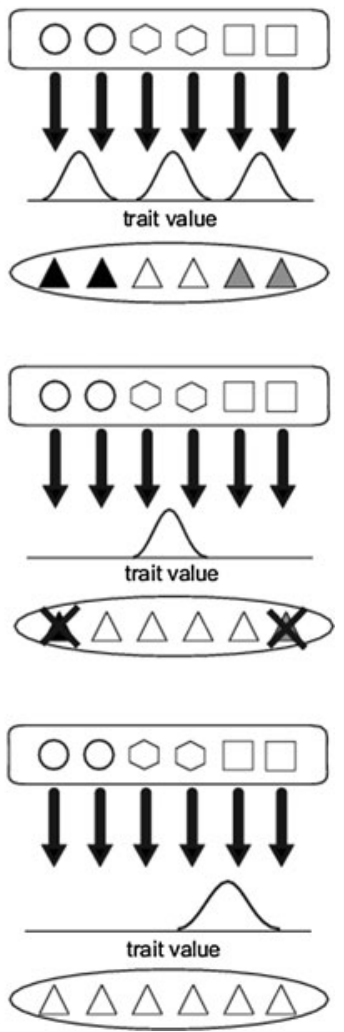
evolutionary outcomes through regulating ecosystem functions.

So far, there is insufficient research to determine conclusively which of these hypotheses is most plausible. In addition, the third hypothesis is not mutually exclusive with the other hypotheses. Species diversity and genetic diversity are the two most important components of biodiversity on Earth. Increasing evidence suggests trait evolution (genetic variation) in a single species influences species diversity as discussed above. In order to understand an interplay between species diversity and genetic diversity, it is worth addressing how not only community composition but also species diversity per se affects evolution in a community.

\section{Future direction: a feedback loop}

This article highlights two reciprocal angles in evolutionary community ecology: (1) how variation in traits within species influences community properties, and (2) how community properties, in particular multiple species interactions and species composition, influence the genetic diversity and realized phenotype of a single species through evolutionary processes. As a result, it is clear that evolutionary processes in community ecology can no longer be ignored. It is evident that there is interdependence between ecological community and evolution in nature, which suggests the existence of a feedback loop between community and evolutionary dynamics.

However, we are only at the beginning of the difficult process of integrating evolutionary principles with the community level. For example, parthenogenetic organisms and clonal plants are typically used in this research area, so the theory of evolution of gamogenetic organisms is not well integrated into evolutionary community ecology. Furthermore, no clear studies have demonstrated the feedback loop between community properties and evolutionary dynamics in a community context in any single system. Both of my studies on community effects on evolution of the leaf beetle preference, and evolutionary impacts of the preference for other community members suggest the existence of a feedback loop between community and evolutionary dynamics in plant-associated arthropod communities. Further studies on such a feedback process should not be typical unidirectional studies that examine effects of evolution on community or community on evolution separate from one another. The next step must be to investigate the feedback loop between community and evolutionary dynamics in nature. We need to examine the extent to which temporal changes in ecological community properties and evolutionary status are actually interdependent, and we should also investigate this feedback in the field as well as in the laboratory. These studies will provide major insights for mechanistic principles for making predictions of community ecology.
Acknowledgments I thank two anonymous reviewers for valuable comments on this manuscript. This study was partially supported by a JSPS young scientist fellowship to S. U. (22-9260).

\section{References}

Agrawal AA (1998) Induced responses to herbivory and increased plant performance. Science 279:1201-1202. doi:10.1126/science. 279.5354.1201

Agrawal AA (2000) Specificity of induced resistance in wild radish: causes and consequences for two specialist and two generalist caterpillars. Oikos 89:493-500

Agrawal AA (2001) Phenotypic plasticity in the interactions and evolution of species. Science 294:321-326

Agrawal AA (2011) Current trends in the evolutionary ecology of plant defence. Funct Ecol 25:420-432. doi:10.1111/j.1365-2435. 2010.01796.x

Agrawal AA, Strauss SY, Stout MJ (1999) Costs of induced responses and tolerance to herbivory in male and female fitness components of wild radish. Evolution 53:1093-1104

Agrawal AA, Conner JK, Johnson MTJ, Wallsgrove R (2002) Ecological genetics of an induced plant defense against herbivores: additive genetic variance and costs of phenotypic plasticity. Evolution 56:2206-2213

Agrawal AA, Ackerly DD, Adler F, Arnold AE, Cáceres C, Doak DF, Post E, Hudson PJ, Maron JL, Mooney KA, Power M, Schemske D, Stachowicz J, Strauss SY, Turner MG, Werner EE (2007) Filling key gaps in population and community ecology. Front Ecol Environ 5:145-152

Alborn HT, Turlings TCJ, Jones TH (1997) An elicitor of plant volatiles from beet armyworm oral secretion. Science 276: 945-949

Anderson P, Agrell J (2005) Within-plant variation in induced defence in developing leaves of cotton plants. Oecologia 144:427-434. doi:10.1007/s00442-005-0095-3

Ando Y, Ohgushi T (2008) Ant- and plant-mediated indirect effects induced by aphid colonization on herbivorous insects on tall goldenrod. Popul Ecol 50:181-189. doi:10.1007/s10144-0070072-2

Bailey JK, Wooley SC, Lindroth RL, Whitham TG (2006) Importance of species interactions to community heritability: a genetic basis to trophic-level interactions. Ecol Lett 9:78-85

Baldwin IT (1998) Jasmonate-induced responses are costly but benefit plants under attack in native populations. Proc Natl Acad Sci USA 95:8113-8118

Bangert RK, Allan GJ, Turek RJ, Wimp GM, Meneses N, Martinsen GD, Keim P, Whitham TG (2006) From genes to geography: a genetic similarity rule for arthropod community structure at multiple geographic scales. Mol Ecol 15:4215-4228. doi:10.1111/j.1365-294X.2006.03092.x

Barbour RC, O'Reilly-Wapstra JM, De Little DW, Jordan GJ, Steane DA, Humphreys JR, Bailey JK, Whitham TG, Potts BM (2009) A geographic mosaic of genetic variation within a foundation tree species and its community-level consequences. Ecology 90:1762-1772

Berenbaum MR, Zangerl AR, Nitao JK (1986) Constraints on chemical coevolution: wild parsnips and the parsnip webworm. Evolution 40:1215-1228

Berg MP, Ellers J (2010) Trait plasticity in species interactions: a driving force of community dynamics. Evol Ecol 24:617-629. doi:10.1007/s10682-009-9347-8

Bingham RA, Agrawal AA (2010) Specificity and trade-offs in the induced plant defence of common milkweed Asclepias syriaca to two lepidopteran herbivores. J Ecol 98:1014-1022. doi: 10.1111/j.1365-2745.2010.01681.x

Bolnick DI, Amarasekare P, Araújo MS, Bürger R, Levine JM, Novak M, Rudolf VHW, Schreiber SJ, Urban MC, Vasseur DA (2011) Why intraspecific trait variation matters in community ecology. Trends Ecol Evol 26:183-192. doi:10.1016/j.tree.2011.01.009 
Bonte D, De Roissart A, Vandegehuchte ML, Ballhorn DJ, Van Leeuwen T, de la Peña E (2010) Local adaptation of aboveground herbivores towards plant phenotypes induced by soil biota. PLoS One 5:e11174. doi:10.1371/journal.pone.0011174

Bukovinszky T, Poelman EH, Gols R, Prekatsakis G, Vet LEM, Harvey JA, Dicke M (2009) Consequences of constitutive and induced variation in plant nutritional quality for immune defence of a herbivore against parasitism. Oecologia 160:299-308. doi:10.1007/s00442-009-1308-y

Campbell DR (1996) Evolution of floral traits in a hermaphroditic plant: field measurements of heritabilities and genetic correlations. Evolution 50:1442-1453

Castagneyrol B, Lagache L, Giffard B, Kremer A, Jactel H (2012) Genetic diversity increases insect herbivory on oak saplings. PLoS One 7:e44247. doi:10.1371/journal.pone.0044247

Cook-Patton SC, McArt SH, Parachnowitsch AL, Thaler JS, Agrawal AA (2011) A direct comparison of the consequences of plant genotypic and species diversity on communities and ecosystem function. Ecology 92:915-923

Craig TP, Itami JK, Ohgushi T, Ando Y, Utsumi S (2011) Bridges and barriers to host shifts resulting from host plant genotypic variation. J Plant Interact 6:141-145. doi:10(1080/17429145), 2010,545148

Crawford KM, Crutsinger GM, Sanders NJ (2007) Host-plant genotypic diversity mediates the distribution of an ecosystem engineer. Ecology 88:2114-2120

Crutsinger GM, Collins MD, Fordyce JA, Gompert Z, Nice CC, Sanders NJ (2006) Plant genotypic diversity predicts community structure and governs an ecosystem process. Science 313:966-968. doi:10.1126/science.1128326

Crutsinger GM, Collins MD, Fordyce JA, Sanders NJ (2008) Temporal dynamics in non-additive responses of arthropods to host-plant genotypic diversity. Oikos 117:255-264. doi: $10.1111 /$ j.2007.0030-1299.16276.x

Darwin CR (1859) On the origin of species by means of natural selection. John Murry, London

de Jong G (1995) Phenotypic plasticity as a product of selection in a variable environment. Am Nat 145:493-512

Duffy JE, Cardinale BJ, France KE, McIntyre PB, Thébault E, Loreau M (2007) The functional role of biodiversity in ecosystems: incorporating trophic complexity. Ecol Lett 10:522-538. doi:10.1111/j.1461-0248.2007.01037.x

Ellers $\mathbf{J}$ (2010) Evolutionary process in community ecology. In: Verhoef HA, Morin PJ (eds) Community ecology: processes, models, and applications. Oxford University Press, New York, pp 151-162

English-Loeb G, Karban R, Walker MA (1998) Genotypic variation in constitutive and induced resistance in grapes against spider mite (Acari: Tetranychidae) herbivores. Environ Entomol 27:297-304

Erb M, Robert CAM, Hibbard BE, Turlings TCJ (2011) Sequence of arrival determines plant-mediated interactions between herbivores. J Ecol 99:7-15. doi:10.1111/j.1365-2745.2010.01757.x

Faeth SH (1986) Indirect interactions between temporally separated herbivores mediated by the host plant. Ecology 67:479-494

Fields MJ, Orians CM (2006) Specificity of phenolic glycoside induction in willow seedlings (Salix sericea) in response to herbivory. J Chem Ecol 32:2647-2656. doi:10.1007/s10886-0069188-7

Fordyce JA (2006) The evolutionary consequences of ecological interactions mediated through phenotypic plasticity. J Exp Biol 209:2377-2383. doi:10.1242/jeb.02271

Fussmann GF, Loreau M, Abrams PA (2007) Eco-evolutionary dynamics of communities and ecosystems. Funct Ecol 21:465-477. doi:10.1111/j.1365-2435.2007.01275.x

Genung MA, Lessard J-P, Brown CB, Bunn WA, Cregger MA, Reynolds WN, Felker-Quinn E, Stevenson ML, Hartley AS, Crutsinger GM, Schweitzer JA, Bailey JK (2010) Non-additive effects of genotypic diversity increase floral abundance and abundance of floral visitors. PLoS One 5:e8711. doi:10.1371 journal.pone.0008711
Gianoli E, Caillaud CM, Chaubet B, Di Pietro JP, Niemeyer HM (1997) Variability in grain aphid (Homoptera: Aphididae) performance and aphid-induced phytochemical responses in wheat. Environ Entomol 26:638-641

Gómez S, Latzel V, Verhulst YM, Stuefer JF (2007) Costs and benefits of induced resistance in a clonal plant network. Oecologia 153:921-930. doi:10.1007/s00442-007-0792-1

Hairston NG, Ellner SP, Geber MA, Yoshida T, Fox JA (2005) Rapid evolution and the convergence of ecological and evolutionary time. Ecol Lett 8:1114-1127. doi:10.1111/j.1461-0248. 2005.00812.x

Haloin JR, Strauss SY (2008) Interplay between ecological communities and evolution. Ann NY Acad Sci 1133:87-125. doi: 10.1196/annals. 1438.003

Hartley SE, Lawton JH (1987) Effects of different types of damage on the chemistry of birch foliage, and the response of birch feeding insects. Oecologia 74:432-437

Havill NP, Raffa KF (1999) Effects of elicitation treatment and genotypic variation on induced resistance in Populus: impacts on gypsy moth (Lepidoptera: Lymantriidae) development and feeding behavior. Oecologia 120:295-303

Hughes AR, Inouye BD, Johnson MTJ, Underwood N, Vellend M (2008) Ecological consequences of genetic diversity. Ecol Lett 11:609-623. doi:10.1111/j.1461-0248.2008.01179.x

Ingram T, Svanbäck R, Kraft NJB, Kratina P, Southcott L, Schluter D (2012) Intraguild predation drives evolutionary niche shift in threespine stickleback. Evolution 66:1819-1832. doi: 10.1111/j.1558-5646.2011.01545.x10.5061/dryad.sj3v479j

Iwao K, Rausher MD (1997) Evolution of plant resistance to multiple herbivores: quantifying diffuse coevolution. Am Nat 149:316-335

Johnson MTJ, Agrawal AA (2005) Plant genotype and environment interact to shape a diverse arthropod community on evening primrose (Oenothera biennis). Ecology 86:874-885

Johnson M, Stinchcombe J (2007) An emerging synthesis between community ecology and evolutionary biology. Trends Ecol Evol 22:250-257. doi:10.1016/j.tree.2007.01.014

Johnson MTJ, Lajeunesse MJ, Agrawal AA (2006) Additive and interactive effects of plant genotypic diversity on arthropod communities and plant fitness. Ecol Lett 9:24-34. doi:10.1111/ j.1461-0248.2005.00833.x

Juenger T, Bergelson J (1998) Pairwise versus diffuse natural selection and the multiple herbivores of scarlet gilia, Ipomopsis aggregata. Evolution 52:1583-1592

Juenger T, Bergelson J (2000) The evolution of compensation to herbivory in scarlet gilia, Ipomopsis aggregata: herbivore-imposed natural selection and the quantitative genetics of tolerance. Evolution 54:764-777

Kant MR, Sabelis MW, Haring MA, Schuurink RC (2008) Intraspecific variation in a generalist herbivore accounts for differential induction and impact of host plant defences. Proc R Soc B 275:443-452. doi:10.1098/rspb.2007.1277

Karban R (1993) Costs and benefits of induced resistance and plant density for a native shrub, Gossypium thurberi. Ecology 74:9-19

Karban R, Baldwin IT (1997) Induced responses to herbivory. University of Chicago Press, Chicago

Kersch-Becker MF, Lewinsohn TM (2012) Bottom-up multitrophic effects in resprouting plants. Ecology 93:9-16

Korth KL, Dixon RA (1997) Evidence for chewing insect-specific molecular events distinct from a general wound response in leaves. Plant Physiol 115:1299-1305

Krause SC, Raffa KF (1992) Comparison of insect, fungal, and mechanically induced defoliation of larch: effects on plant productivity and subsequent host susceptibility. Oecologia 90:411-416

Lankau RA, Strauss SY (2007) Mutual feedbacks maintain both genetic and species diversity in a plant community. Science 317:1561-1563. doi:10.116/science.1147455

Lankau RA, Strauss SY (2008) Community complexity drives patterns of natural selection on a chemical defense of Brassica nigra. Am Nat 171:150-161. doi:10.1086/524959 
Lavergne S, Mouquet N, Thuiller W, Ronce O (2010) Biodiversity and climate change: integrating evolutionary and ecological responses of species and communities. Annu Rev Ecol Evol Syst 41:321-350. doi:10.1146/annurev-ecolsys-102209-144628

Leimu R, Koricheva J (2006) A meta-analysis of genetic correlations between plant resistances to multiple enemies. Am Nat 168:E15-E37. doi:10.1086/505766

Lin H, Kogan M, Fischer D (1990) Induced resistance in soybean to the Mexican bean beetle (Coleoptera: Coccinellidae): comparisons of inducing factors. Environ Entomol 19:1852-1857

Loreau M (2010) From populations to ecosystems: theoretical foundation for a new ecological synthesis. Princeton University Press, Princeton

Martinsen GD, Driebe EM, Whitham TG (1998) Indirect interactions mediated by changing plant chemistry: beaver browsing benefits beetles. Ecology 79:192-200

Masters GJ, Jones TH, Rogers M (2001) Host-plant mediated effects of root herbivory on insect seed predators and their parasitoids. Oecologia 127:246-250. doi:10.1007/s004420000569

Mattiacci L, Rudelli S, Rocca BA, Genini S, Dorn S (2001) Systemically-induced response of cabbage plants against a specialist herbivore, Pieris brassicae. Chemoecology 11:167-173

McCloud ES, Baldwin IT (1997) Herbivory and caterpillar regurgitant amplify the wound-induced increases in jasmonic acid but not nicotine in Nicotiana sylvestris. Planta 203:430-435

McGuire RJ, Johnson MTJ (2006) Plant genotype and induced responses affect resistance to herbivores on evening primrose (Oenothera biennis). Ecol Entomol 31:20-31

McNaughton SJ (1983) Compensatory plant growth as a response to herbivory. Oikos 40:329-336

Nakamura M, Miyamoto Y, Ohgushi T (2003) Gall initiation enhances the availability of food resources for herbivorous insects. Funct Ecol 17:851-857

Ohgushi T (2005) Indirect interaction webs: herbivore-induced effects through trait change in plants. Annu Rev Ecol Evol Syst 36:81-105. doi:10.1146/annurev.ecolsys.36.091704.175523

Olsson K, Agren J (2002) Latitudinal population differentiation in phenology, life history and flower morphology in the perennial herb Lythrum salicaria. J Evol Biol 15:983-996

O'Neil P (1997) Natural selection on genetically correlated phenological characters in Lythrum salicaria L. (Lythraceae). Evolution 51:267-274

Orians CM, Jones CG (2001) Plants as resource mosaics: a functional model for predicting patterns of within-plant resource heterogeneity to consumers based on vascular architecture and local environmental variability. Oikos 94:493-504

Palkovacs EP, Post DM (2008) Eco-evolutionary interactions between predators and prey: can predator-induced changes to prey communities feed back to shape predator foraging traits? Evol Ecol Res 20:699-720

Pavia H, Toth GB (2000) Inducible chemical resistance to herbivory in the brown seaweed Ascophyllum nodosum. Ecology $81: 3212-3225$

Pilson D (1996) Two herbivores and constraints on selection for resistance in Brassica rapa. Evolution 50:1492-1500

Poelman EH, van Loon JJA, Dicke M (2008) Consequences of variation in plant defense for biodiversity at higher trophic levels. Trends Plant Sci 13:534-541. doi:10.1016/j.tplants.2008.08.003

Poelman EH, Van Loon JJA, Van Dam NM, Vet LEM, Dicke M (2010) Herbivore-induced plant responses in Brassica oleracea prevail over effects of constitutive resistance and result in enhanced herbivore attack. Ecol Entomol 35:240-247

Poelman EH, Gols R, Snoeren TAL, Muru D, Smid HM, Dicke M (2011) Indirect plant-mediated interactions among parasitoid larvae. Ecol Lett 14:670-676. doi:10.1111/j.1461-0248.2011.01629.x

Post DM, Palkovacs EP (2009) Eco-evolutionary feedbacks in community and ecosystem ecology: interactions between the ecological theatre and the evolutionary play. Philos Trans R Soc B 364:1629-1640. doi:10.1098/rstb.2009.0012

Rodriuguez-Saona C, Thaler JS (2005) Herbivore-induced responses and patch heterogeneity affect abundance of arthropods on plants. Ecol Entomol 30:156-163
Sauge M-H, Mus F, Lacroze J-P, Pascal T, Kervella J, Poëssel J-L (2006) Genotypic variation in induced resistance and induced susceptibility in the peach-Myzus persicae aphid system. Oikos 113:305-313

Schoener TW (2011) The newest synthesis: understanding the interplay of evolutionary and ecological dynamics. Science 331:426-429

Snoeren TAL, Kappers IF, Broekgaarden C, Mumm R, Dicke M, Bouwmeester HJ (2010) Natural variation in herbivore-induced volatiles in Arabidopsis thaliana. J Exp Bot 61:3041-3056. doi: $10.1093 / \mathrm{jxb} / \mathrm{erq} 127$

Stinchcombe J, Rausher MD (2001) Diffuse selection on resistance to deer herbivory in the ivyleaf morning glory, Ipomoea hederacea. Am Nat 158:376-388

Stinchcombe JR, Rausher MD (2002) The evolution of tolerance to deer herbivory: modifications caused by the abundance of insect herbivores. Proc R Soc B 269:1241-1246. doi:10.1098/rspb. 2002.2015

Strauss SY, Agrawal AA (1999) The ecology and evolution of plant tolerance to herbivory. Trends Ecol Evol 14:179-185

Strauss SY, Sahli H, Conner JK (2005) Toward a more trait-centered approach to diffuse (co)evolution. New Phytol 165:81-90. doi:10.1111/j.1469-8137.2004.01228.x

Sultan SE, Bazzaz FA (1993) Phenotypic plasticity in Polygonum persicaria. I. Diversity and uniformity in genotypic norms of reaction to light. Evolution 47:1009-1031

Tack AJM, Roslin T (2011) The relative importance of host-plant genetic diversity in structuring the associated herbivore community. Ecology 92:1594-1604

Takabayashi J, Shimoda T, Dicke M, Ashihara W, Takafuji A (2000) Induced response of tomato plants to injury by green and red strains of Tetranychus urticae. Exp Appl Acarol 24: 377-383

terHorst CP (2010) Evolution in response to direct and indirect ecological effects in pitcher plant inquiline communities. Am Nat 176:675-685. doi:10.1086/657047

Tétrad-Jones C, Kertesz MA, Gallois P, Preziosi RF (2007) Genotype-by-genotype interactions modified by a third species in a plant-insect system. Am Nat 170:491-499

Tian D, Traw MB, Chen JQ, Kreitman M, Bergelson J (2003) Fitness costs of R-gene-mediated resistance in Arabidopsis thaliana. Nature 423:74-77. doi:10.1038/nature01588

Travers-Martin N, Müller C (2007) Specificity of induction responses in Sinapis alba L. and their effects on a specialist herbivore. J Chem Ecol 33:1582-1597. doi:10.1007/s10886-0079322-1

Turlings TCJ, Tumlinson JH, Lewis WJ (1990) Exploitation of herbivore-induced plant odors by host-seeking parasitic wasps. Science 250:1251-1253

Underwood N (2004) Variance and skew of the distribution of plant quality influence herbivore population dynamics. Ecology $85: 686-693$

Underwood N (2009) Effect of genetic variance in plant quality on the population dynamics of a herbivorous insect. $\mathbf{J}$ Anim Ecol 78:839-847. doi:10.1111/j.1365-2656.2009.01540.x

Underwood N, Morris W, Gross K, Lockwood JR III (2000) Induced resistance to Mexican bean beetles in soybean: variation among genotypes and lack of correlation with constitutive resistance. Oecologia 122:83-89

Urban M, Leibold M, Amarasekare P, Demeester L, Gomulkiewicz R, Hochberg M, Klausmeier C, Loeuille N, Demazancourt C, Norberg J (2008) The evolutionary ecology of metacommunities. Trends Ecol Evol 23:311-317. doi:10.1016/ j.tree.2008.02.007

Utsumi S (2011) Eco-evolutionary dynamics in herbivorous insect communities mediated by induced plant responses. Popul Ecol 53:23-34. doi:10.1007/s10144-010-0253-2

Utsumi S, Ohgushi T (2007) Plant regrowth response to a stemboring insect: a swift moth-willow system. Popul Ecol 49: 241-248. doi:10.1007/s10144-007-0042-8

Utsumi S, Ohgushi T (2008) Host plant variation in plant-mediated indirect effects: moth boring-induced susceptibility of willows to 
a specialist leaf beetle. Ecol Entomol 33:250-260. doi:10.1111/ j.1365-2311.2007.00959.x

Utsumi S, Ohgushi T (2009) Community-wide impacts of herbivore-induced plant regrowth on arthropods in a multi-willow species system. Oikos 118:1805-1815. doi:10.1111/j.1600-0706. 2009.17580.X

Utsumi S, Ando Y, Ohgushi T (2009a) Evolution of feeding preference in a leaf beetle: the importance of phenotypic plasticity of a host plant. Ecol Lett 12:920-929. doi:10.1111/j.1461-0248. 2009.01349.x

Utsumi S, Nakamura M, Ohgushi T (2009b) Community consequences of herbivore-induced bottom-up trophic cascades: the importance of resource heterogeneity. J Anim Ecol 78:953-963. doi:10.1111/j.1365-2656.2009.01570.x

Utsumi S, Ando Y, Miki T (2010) Linkages among trait-mediated indirect effects: a new framework for the indirect interaction web. Popul Ecol 52:485-497. doi:10.1007/s10144-010-0237-2

Utsumi S, Ando Y, Craig TP, Ohgushi T (2011) Plant genotypic diversity increases population size of a herbivorous insect. Proc R Soc B 278:3108-3115. doi:10.1098/rspb.2011.0239

Utsumi S, Ando Y, Roininen H, Takahashi J, Ohgushi T (2013) Herbivore community promotes trait evolution in a leaf beetle via induced plant response. Ecol Lett 16:362-370. doi:10.1111 ele. 12051

van Dam NM, Vrieling K (1994) Genetic variation in constitutive and inducible pyrrolizidine alkaloid levels in Cynoglossum officinale L. Oecologia 99:374-378

Van Kleunen M, Fischer M (2005) Constraints on the evolution of adaptive phenotypic plasticity in plants. New Phytol 166:49-60. doi:10.1111/j.1469-8137.2004.01296.x

Van Zandt PA, Agrawal AA (2004) Specificity of induced plant responses to specialist herbivores of the common milkweed Asclepias syriaca. Oikos 104:401-409

Van Zandt PA, Agwaral AA (2004) Community-wide impacts of herbivore-induced plant responses in milkweed (Asclepias syriaca). Ecology 85:2626-2629

Vavrek MC (1998) Within-population genetic diversity of Taraxacum officinale (Asteraceae): differential genotype response and effect on interspecific competition. Am J Bot 85:942-954
Vellend M, Geber MA (2005) Connections between species diversity and genetic diversity. Ecol Lett 8:767-781. doi:10.1111/ j.1461-0248.2005.00775.x

Via S, Lande R (1985) Genotype-environment interaction and the evolution of phenotypic plasticity. Evolution 39:505-522

Violle C, Enquist BJ, McGill BJ, Albert CH, Hulshof C, Jung V, Messier J (2012) The return of the variance: intraspecific variability in community ecology. Trends Ecol Evol 27:244-252

Viswanathan DV, Thaler JS (2004) Plant vascular architecture and within-plant spatial patterns in resource quality following herbivory. J Chem Ecol 30:531-543

Voelckel C, Baldwin IT (2004) Herbivore-induced plant vaccination. Part II. Array-studies reveal the transience of herbivorespecific transcriptional imprints and a distinct imprint from stress combinations. Plant J 38:650-663

Vrieling K, Smit W, van der Meijden E (1991) Tritrophic interactions between aphids (Aphis jacobaeae Schrank), ant species, Tyria jacobaeae L., and Senecio jacobaea L. lead to maintenance of genetic variation in pyrrolizidine alkaloid. Oecologia $86: 177-182$

Whitham TG, Bailey JK, Schweitzer JA, Shuster SM, Bangert RK, LeRoy CJ, Lonsdorf EV, Allan GJ, DiFazio SP, Potts BM, Fischer DG, Gehring CA, Lindroth RL, Marks JC, Hart SC, Wimp GM, Wooley SC (2006) A framework for community and ecosystem genetics: from genes to ecosystems. Nat Rev Genet 7:510-523. doi:10.1038/nrg1877

Wimp GM, Martinsen GD, Floate KD, Bangert RK, Whitham TG (2005) Plant genetic determinants of arthropod community structure and diversity. Evolution 59:61-69

Zangerl AR, Berenbaum MR (1990) Furanocoumarin induction in wild parsnip: genetics and population variation. Ecology 71:1933-1940

Zavala JA, Baldwin IT (2004) Fitness benefits of trypsin proteinase inhibitor expression in Nicotiana attenuata are greater than their costs when plants are attacked. BMC Ecol 4:11. doi: $10.1186 / 1472-6785-4-11$

Züst T, Heichinger C, Grossniklaus U, Harrington R, Kliebenstein DJ, Turnbull LA (2012) Natural enemies drive geographic variation in plant defenses. Science 338:116-119. doi:10.1126/ science. 1226397 